Influenza and Immunity-(continued).

ture within five days. Also, with regard to this return voyage, a particularly interesting comparison may be drawn. A troop transport sailing at the same time and in company, with men infected in the same area but for the first time, showed, in spite of far better hygienic surroundings, a casualty list proportionately seven times heavier than our own

Even up to this point the developed immunity seems quite definite, but the sequel is important and gives further proof in that, four months later, although several times in contact with the disease in Great Britain, America, and Canada, only six catarrhal cases occurred in the ship, and these only very mild in degree. For all practical purposes the ship's company can be taken as the same throughout, very few changes in personnel taking place and nearly all the hospital cases being returned to the ship after convalescence.

The Chief Deduction.

It is beside the point here to describe prophylactic measures, attempts at isolation, disinfection, and the many ways in which the bacteria, once inside the ship, were counter-attacked, for it is to the main issue that the chief deduction from these notes must lead. Superficial as the bacteriological work in a ship had perforce to be, there was a decided and definite recurrence of the typical pathological streptococci. The antitoxic powers of streptococcic sera are well established. The artificially immunised animal is a common experimental, even commercial entity. Take this organism as the common cause of the severer complications, largely responsible for the high mortality and entirely free from limitations of action generally ascribed to the accompanying bacillus, and it is seen that many of the abnormalities in these outbreaks can be explained as due to our " influenza" being a subacute streptococcal infection. To such we may grant the certainty of some acquired immunity, be the invasion acute or so slight as to pass unnoticed. Working under cover and behind the screen of the coccal predominance we can picture the bacilli, but exactly how $B$. Influenza has changed, if at all, is beyond the scope of such rough notes as these, where the attempt is to point out that immunity is developed to the mixed bacteria as a whole. And to this end one must impress three facts, namely, that many of the ship's cases were definite mixed infections, that the men were again exposed to similar combinations of germs, and that a considerable degree of immunity was at once exhibited.

Doubtless many such experiences might be cited, and, by the time we have the statements of the innumerable officialdoms of the world at war and the true picture of the disease in detail and perspective, it will be more than interesting to learn whether we are to describe the true causes of its abnormalities as complications of circumstance and distribution, disguising the habits of very wellknown organisms, or as appearances of new bacterial forms, deserving of special description. Evidence favours the former, though, as yet, incompletely. The final decision must come later, but does not primarily concern us here. There may be bacilli, pneumococci, and streptococci in their many forms, all liable to take action in the human body. More than one authority has denied to these the right of distinctive names and classified them merely as metamorphoses of a common ancestor. But one would, apart from such considerations, call attention to presence amongst us of thousands of people who have gained a marked immunity to influenza attacks. Why should we not make a general attempt to immunise the masses?

It has been done with remarkable success in the case of the typhoid group of infections. These diseases, in their most destructive form, are practically wiped out, and it must be recalled that already many extremely successful protective inoculations have been made against influenza. The details of the preparations employed are not at present well collected and described, but would appear to comprise mixed vaccines derived from the usually recognised catarrhal organisms. It is known that their use in certain well-known schools and Service establishments has led to almost complete protection against the disease.

Such facts can be gleaned from the literature, and, adding the accumulation of such small experiences as here described, there are the strongest indications for a beliei in acquired resistance. The combination of proved results from both inoculation and auto-inoculation should make a powerful case for those who would urge and develop the prophylactic value of protective injections. With typhoid they led to one of the great medical victories of our time. May we hope for equal success in the combat with this latest scourge? It would seem to be an attainable ambition and worthy of the highest endeavour.

\title{
THE STUDY OF INDUSTRIAL FATIGUE.
}

A strong Committee has been formed under the chairmanship of Professor Sherrington, F.R.S., for the study of this subject, and we would commend to it the inclusion in its labours of a study of industrial fatigue in nurses. In many branches of Labour, artizans have secured a working day of eight hours, with less on Saturday and none on Sunday - a working week of 54 hours, and in some trades agitations and even strikes are in progress for still shorter hours; but a nurse's working day is never less than ten hours, even when she has a colleague to relieve her of night duty. She may have one afternoon a week off duty, and an occasional Sunday, but in private nursing she is never secure of these, and in very many cases she is on duty both day and night, and gets her sleep when she can. She goes to bed at night, it is true, but in very many cases in private nursing she is liable to be called up, sometimes two or three times in the night, and for weeks together never has an uninterrupted night's sleep. At the end of some weeks of this, she goes back to the institution to which she belongs, and in times of epidemics may be sent off within an hour or two to another case.

This sweating of nurses is one of the matters that should engage the attention of the Royal College of Nursing, The College will be, if it is not already, a very powerful body in all that concerns nursing, and it might even now do worse than call the attention of Dr. Sherrington's Committee to industrial fatigue as it is manifested in overworked nurses. 